\title{
Penilaian kualitas akustik masjid raudhaturrahmah Padang Tiji dengan menggunakan simulasi ecotect
}

\section{Yulida Yani}

Program Studi Arsitektur, Fakultas Sains dan Teknologi, Universitas Islam Negeri Ar-Raniry yulidayani99@gmail.com

\begin{tabular}{l}
\hline Informasi artikel \\
\hline Sejarah artikel: \\
Diterima \\
Revisi \\
Dipublikasikan \\
\hline
\end{tabular}

\begin{abstract}
ABSTRAK
Masjid merupakan tempat ibadah umat islam yang memiliki pengaruh penting bagi masyarakat, dalam melakukan ibadah perlu adanya ketenangan dan kejelasan bicara agar pesan yang disampaikan dapat tersalurkan dengan jelas dan baik. Dalam penelitian ini ruang yang digunakan untuk simulasi ialah ruang shalat masjid Raudhaturrahmah. Tujuan penelitian adalah untuk mengetahui kondisi, penyebabnya dan memperbaiki kualitas akustik dengan penambahan plafond serta material serap, agar sesuai dengan kebutuhan ruang percakapan masjid. Fokus utama penelitian adalah menghitung tingkat bising latar belakang (background noise), dan waktu dengung (reverberation time). Metode yang digunakan adalah simulasi dengan menggunakan software Ecotect yang mampu menganalisis kinerja akustik. Hasil dari simulasi memperlihatkan bahwa kalkulasi waktu dengung (RT) dan pengukuran background noise belum memenuhi kriteria yang telah ditetapkan. nilai yang dihasilkan untuk RT dengan occupancy 0\%, 50\%, I00\% ialah I8,29 s, 7,80 s, dan 4, 7I s. sedangkan hasil dari background Noise ialah 60 dB. Dari penelitian ini menghasilkan solusi untuk memperbaiki waktu dengung dan background noise dengan menambah plafond dan material serap. Setelah penambahan Plafond dan material serap nilai akustik yang dihasilkan lebih optimal dibandingkan dengan kondisi exiting.
\end{abstract}

Kata kunci:

Masjid

Akustik

Waktu Dengung (RT)

Background Noise

Ecotect

\section{Key word:}

Mosque

Acoustic

Reverberation Time (RT)

Background Noise

Ecotect

\begin{abstract}
The mosque is a place of worship of Muslims who have an important influence on the community, in conducting worship there needs to be calm and clarity of speech so that the message conveyed can be channeled clearly and well. In this study the space used for the simulation is the prayer room of the Raudhaturrahmah mosque. The purpose of this study was to determine the conditions, their causes and improve the quality of acoustics by adding ceilings and absorbent material, to suit the needs of the mosque's conversation room. The main focus of the study is to calculate the level of background noise (background noise), and reverberation time. The method used is a simulation using Ecotect software that is able to analyze acoustic performance. The results of the simulation show that the calculation of reverberation time (RT) and measurement of background noise do not meet established criteria. The resulting value for RTs with occupancy of $0 \%$, $50 \%, 100 \%$ is $18.29 \mathrm{~s}, 7.80 \mathrm{~s}$, and 4, 7I s. while the result of background noise is $60 \mathrm{~dB}$. From this study produced a solution to improve the reverberation time and background noise by adding ceiling and absorbent material. After the addition of ceiling and material absorption the acoustic value produced is more optimal compared to the exiting conditions.
\end{abstract}

Copyright (C) 2018 Universitas Widya Mataram Yogyakarta. All Right Reserved

\section{Pendahuluan}

Masjid Raudhaturrahman salah satu masjid yang memiliki bentuk bangunan yang unik yaitu menggunakan atap kubah sempurna hingga menutupi seluruh bidang bangunan. Di dalam sebuah penelitian yang diteliti oleh dosen Teknik Fisika ITB mengatakan bahwa kubah sempurna atau berbentuk cekung dapat memberikan gangguan akustik yang lebih signifikan (sarwono, 2005). Ada teori lain yang mengatakan bahwa bentuk cekung bersifat pemusatan suara yang tidak menyebar. Bentuk ini 
menimbulkan efek vocal point atau sebagai pusat arah pantulan suara dan memunculkan gema yang merambat. Permukaan cekung akan memantulkan suara terfokus ketitik yang sama. Penelitian ini juga didukung oleh penelitian yang pernah diteliti tentang kinerja akustik yang terjadi pada masjid Raudhaturrahmah. Dalam penelitian tersebut dihasilkan bahwa masjid Raudhaturrahmah mengalami cacat akustik yang cukup serius. Akibatnya pelaksanaan ibadah didalamnya sangat terganggu (Priandi, 20I2).

Berdasarkan hasil wawancara jamaah masjid raudhaturrahmah pada tiji, sebagian dari mereka mengatakan bahwa masjid ini menghasilkan suara yang menggema dan juga menghasilkan kebisingan yang dihasilkan dari arah jalan raya, sehingga sangat mengganggu aktivitas didalam masjid. Dan masalah ini bisa berdampak pada psikologis manusia, seperti menghilangkan kenyamanan dan kosentrasi. Dengan demikian, untuk mendapatkan kualitas akustik yang baik sudah seharusnya dilakukan untuk bangunan yang memiliki pengaruh penting terhadap masyarakat. Dan masjid merupakan salah satu bangunan yang harus diperhatikan kualitas fungsinya, karena kualitas akustik masjid akan mempengaruhi pemahaman isi ceramah dalam suatu kegitan. Untuk menciptakan kondisi tersebut, perlu diperhatikan dan mengoptimalkan kondisi akustik didalam masjid agar bisa dipastikan bunyi suara dari imam atau khatib dapat didengardengan jelas oleh semua jamaah. Dengan kondisi akustik yang optimal para jamaah dapat meningkatkankenyamanan dan kosentrasi dalam melakukan aktifitas ibadah yang berlangsung.

Dalam hal ini ini peneliti akan menyelidiki kinerja akustik ruang dalam masjid Raudhaturrahman dengan membuat simulasi dan modeling menggunakan software computer (ecotect), agar dapat mengetahui kondisi, penyebabnya dan bisa memberikan solusi untuk mencapai nilai akustik yang baik dan optimal pada ruang dalam masjid Raudhaturrahman.

\section{Metode}

Penelitian ini di fokuskan pada pengukuran paramater background noise dan waktu dengung (reverberation time). Untuk pengumpulan data yang digunakan dalam penelitian ini ialah, observasi, studi literatur, dan wawancara. Metode yang digunakan dalam penelitian ini adalah metode simulasi. simulasi didefinisikan sebagai sebuah system dinamik yang menggunakan model computer dengan tujuan mengevaluasi dan meningkatkan kinerja system (Harrel dkk, 2004). Dalam penelitian ini simulasi akan di uji dengan menggunakan software Autodesk Ecotect yang merupakan sebuah sotware yang digunakan untuk melakukan simulasi akustik yang melibatkan geometri dan parameter akustik pada elemen arsitektur didalam ruang. Metode dalam menganalisis data dalam penelitian ini dilakukan dengan cara menggunakan analisis deskriptif. Yaitu dengan cara menggambarkan atau menjelaskan hasil analisis yang dihasilkan dari data pengukuran dan hasil simulasi (Hasan 200I) deskriptif hanya berhubungan dengan hal menguraikan atau memberikan keterangan-keterangan mengenai suatu data atau keadaan. Dengan kata deskriptif berfungsi menerangkan keadaan, gejala, atau persoalan. Dalam penelitian ini peneliti akan mendeskripsikan hasil dari pengukuran background noise dan waktu dengung dalam garfik dan tabel dengan dasar teori yang ada. 
a. Proses Penelitian

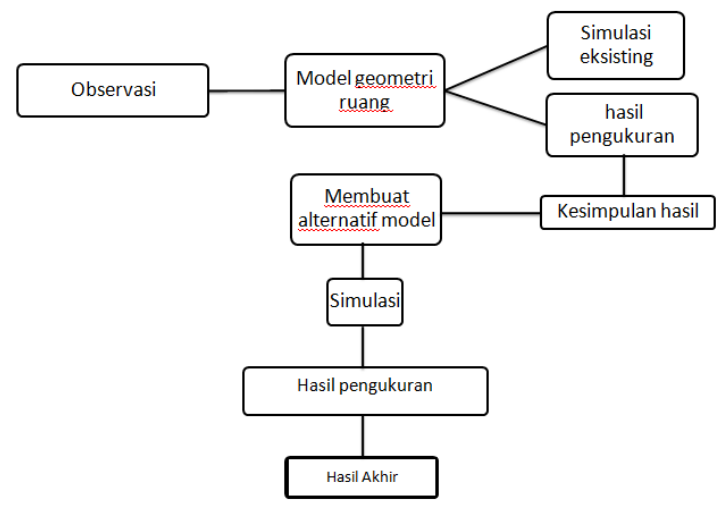

Gambar 3 diagram alur simulasi

(Sumber: Analisa Pribadi)

\section{Hasil dan pembahasan}

a. Hasil Background Noise

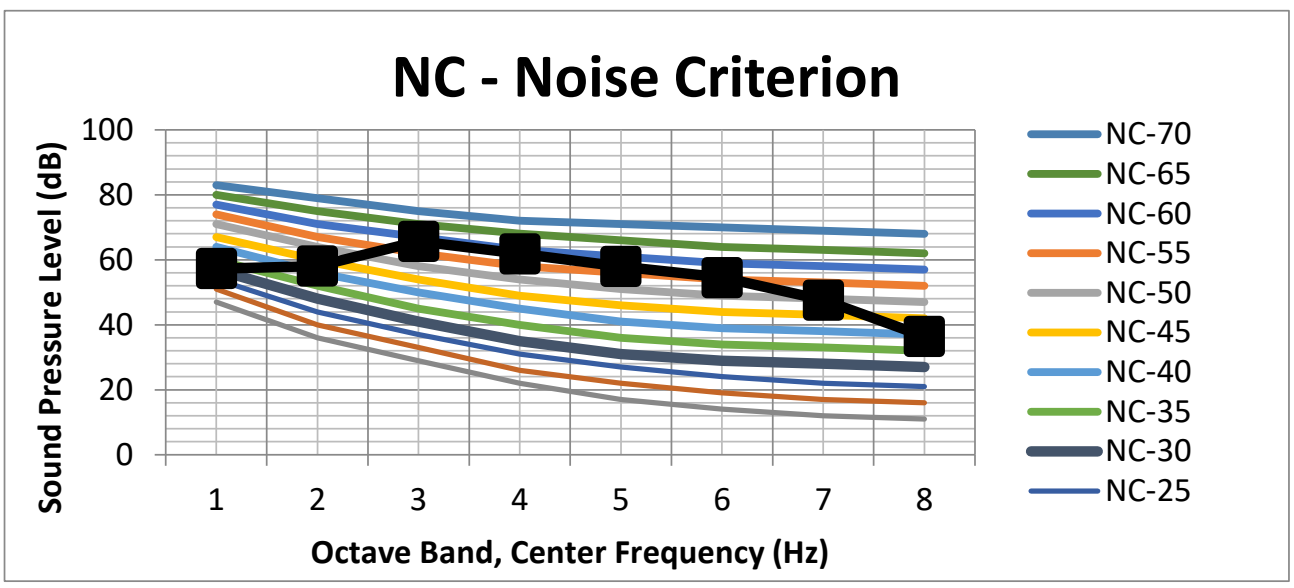

Gambar 4 grafik NC background Noise (Sumber: Analisis Pribadi)

Pengukuran background noise pada Masjid Raudhaturrahmah diperoleh hasil rata-rata yang sangat tinggi yaitu mencapai $60 \mathrm{~dB}$. Nilai tersebut jauh di atas syarat bising background noise yang diperbolehkan untuk masjid yang fungsinya sebagai bangunan ibadah, yaitu 25-35 dB (Doelle,1990). Background noise yang tinggi sangat dimungkinkan karena lokasi masjid berada di dekat jalan raya dan hampir seluruh permukaan dinding adalah bukaan.

\section{b. Hasil Analisis Waktu Dengung}

Perhitungan volume ruang dalam masjid Raudhaturrahman menggunakan software Ecotect mempunyai volume ruang sebesar $9759.170 \mathrm{~m} 3$ dengan luas permukaan serap yaitu $3069.330 \mathrm{~m} 2$. Dan waktu dengung yang optimum untuk ruang masjid yang mempunyai volume 9759.170 ialah I.0 s.

Material yang digunakan di dalam ruang masjid tersebut ada lima jenis dengan koefisien absorsi yang berbeda-beda sebagai berikut : 
Tabel 2 Nilai absorsi material

\begin{tabular}{|r|l|r|r|r|r|r|r|r|r|r|}
\hline \multirow{2}{*}{ no } & \multicolumn{1}{|c|}{ Material } & \multicolumn{10}{|c|}{ Frekuensi } \\
\cline { 3 - 12 } & & 63 & I25 & 250 & 500 & I000 & 2000 & 4000 & 8000 & $\mathrm{I} 6000$ \\
\hline $\mathrm{I}$ & suspended concrete ceiling & $0,0 \mathrm{I}$ & 0,02 & 0,02 & 0,02 & 0,03 & 0,04 & 0,05 & 0,06 & 0,06 \\
\hline 2 & concslab tiles onground & $0,0 \mathrm{I}$ & $0,0 \mathrm{I}$ & $0,0 \mathrm{I}$ & $0,0 \mathrm{I}$ & 0,02 & 0,03 & 0,07 & 0,07 & 0,09 \\
\hline 3 & framed plywood partision & $0, \mathrm{I} 7$ & $0, \mathrm{I}$ & 0,07 & 0,07 & 0,08 & 0,05 & 0,04 & 0,05 & 0,04 \\
\hline 4 & solidcore pine timber & $0, \mathrm{I} 7$ & $0, \mathrm{I} 4$ & $0, \mathrm{I} 2$ & 0,08 & 0,08 & 0,07 & 0,06 & 0,05 & 0,04 \\
\hline 5 & cement plaster & & & & & & & & & \\
\hline
\end{tabular}

(sumber : analisis ecotect)

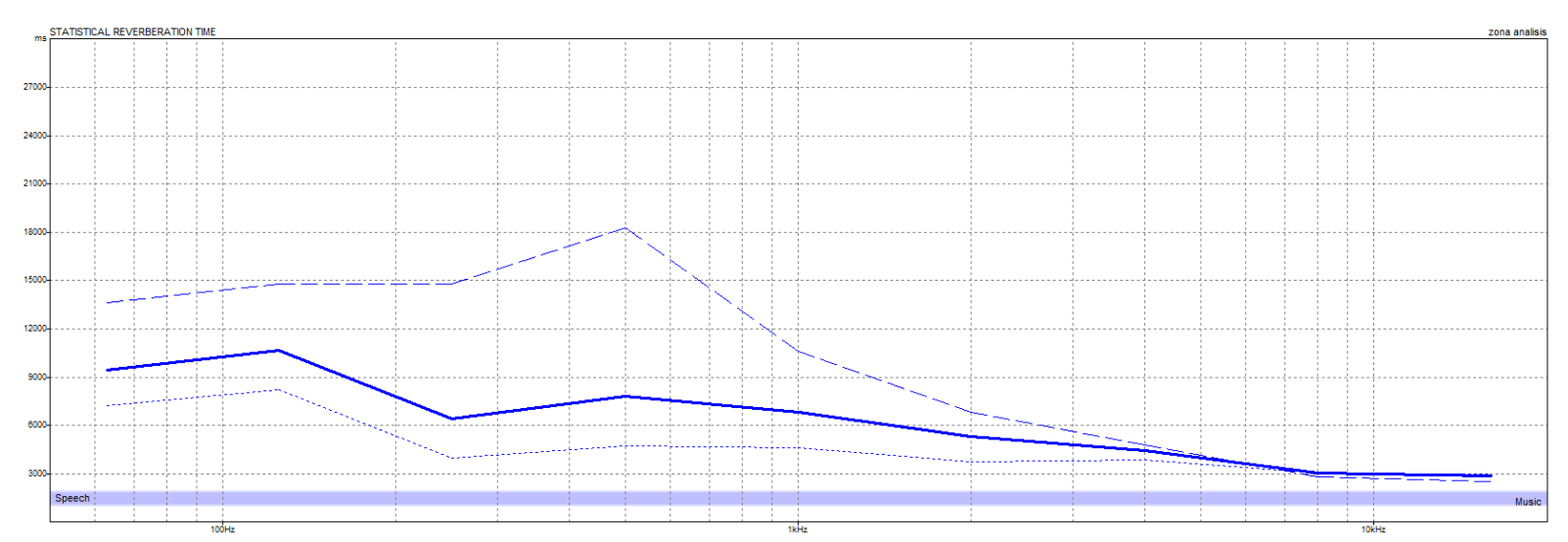

Gambar 5 grafik waktu dengung kondisi existing

(Sumber: Analisis Ecotect)

Tabel 3 Hasil analisis nilai waktu dengung occupancy 0\%. 50\%, dan I00\%

\begin{tabular}{|l|c|c|c|c|}
\hline & TOTAL & EMPTY & $50 \%$ & FULL \\
\hline FREQ: & ABSPT. & RT(60) & RT(60) & RT(60) \\
\hline------ & ------ & ------ & ------ & ----- \\
\hline $63 \mathrm{~Hz}:$ & $\mathrm{II0.242}$ & $\mathrm{I} 3.65$ & 9.46 & 7.22 \\
\hline $\mathrm{I} 25 \mathrm{~Hz}:$ & 94.656 & $\mathrm{I} 4.8 \mathrm{I}$ & 10.66 & 8.25 \\
\hline $250 \mathrm{~Hz}:$ & 87.857 & $\mathrm{I} 4.78$ & 6.42 & $4.0 \mathrm{I}$ \\
\hline $500 \mathrm{~Hz}:$ & $57.9 \mathrm{I} 7$ & $\mathrm{I} .29$ & 7.80 & 4.72 \\
\hline $\mathrm{IkHz:}$ & 83.584 & $\mathrm{I} .60$ & 6.83 & 4.62 \\
\hline $2 \mathrm{kHz}:$ & 100.843 & 6.85 & 5.30 & 3.75 \\
\hline $4 \mathrm{kHz}:$ & $\mathrm{I} 55.895$ & 4.77 & 4.47 & 3.88 \\
\hline $8 \mathrm{kHz}:$ & $\mathrm{I} 66.96 \mathrm{I}$ & 2.83 & 3.07 & 3.06 \\
\hline $\mathrm{I} 6 \mathrm{kHz}:$ & $\mathrm{I} 40.972$ & 2.54 & 2.86 & 3.00 \\
\hline
\end{tabular}

(sumber : analisis ecotect)

Table dan gambar di atas menunjukkan hasil analisis waktu dengung yang dihasilkan di dalam masjid Raudhaturahman dengan pengguna ruang yang berbeda.

Berdasarkan hasil tabel di atas pada frekuensi $500 \mathrm{~Hz}$ dengan pengguna ruang (occupancy) $0 \%$ mencapai nilai RT I8,29 s, pengguna ruang (occupancy) 50\%:7.80 s, pengguna ruang (occupancy) I00\% : 4,72 s. Ketika masjid terisi penuh dengan jamaah, nilai RT mengalami penurunan, dikarenakan tubuh manusia juga merupakan absorber. (Syamsiyah, 20I4). Hal ini juga didukung oleh penelitian yang dilakukan (Priandi, 20I2) pada masjid Raudhaturrhamah juga menghasilkan nilai RT berkisar 2.2-8,5 s dengan uji pemodelan CATT-Acostic. hasil tersebut menunjukkan nilai selisih yang sangat kecil, hampir 
sama dengan hasil yang dihasilkan menggunakan simulasi software Ecotect pada occupancy 50\%- I00\%. Akan tetapi nilai RT yang dihasilkan ketika ruang terisi juga belum mencapai nilai optimum yang sesuai dengan volume ruang masjid. (Mediastika,2005). Masjid ini mengalami cacat akustik yang sangat signifikan dan menyebabkan ketidakjelasan suara.

\section{c. Hasil Simulasi Rays Dan Particles}

Simulasi rays dan particles ini dilakukan untuk dapat melihat secara visual perilaku bunyi pada speaker. dibawah ini merupakan gambaran perjalanan suara beberapa spiker:
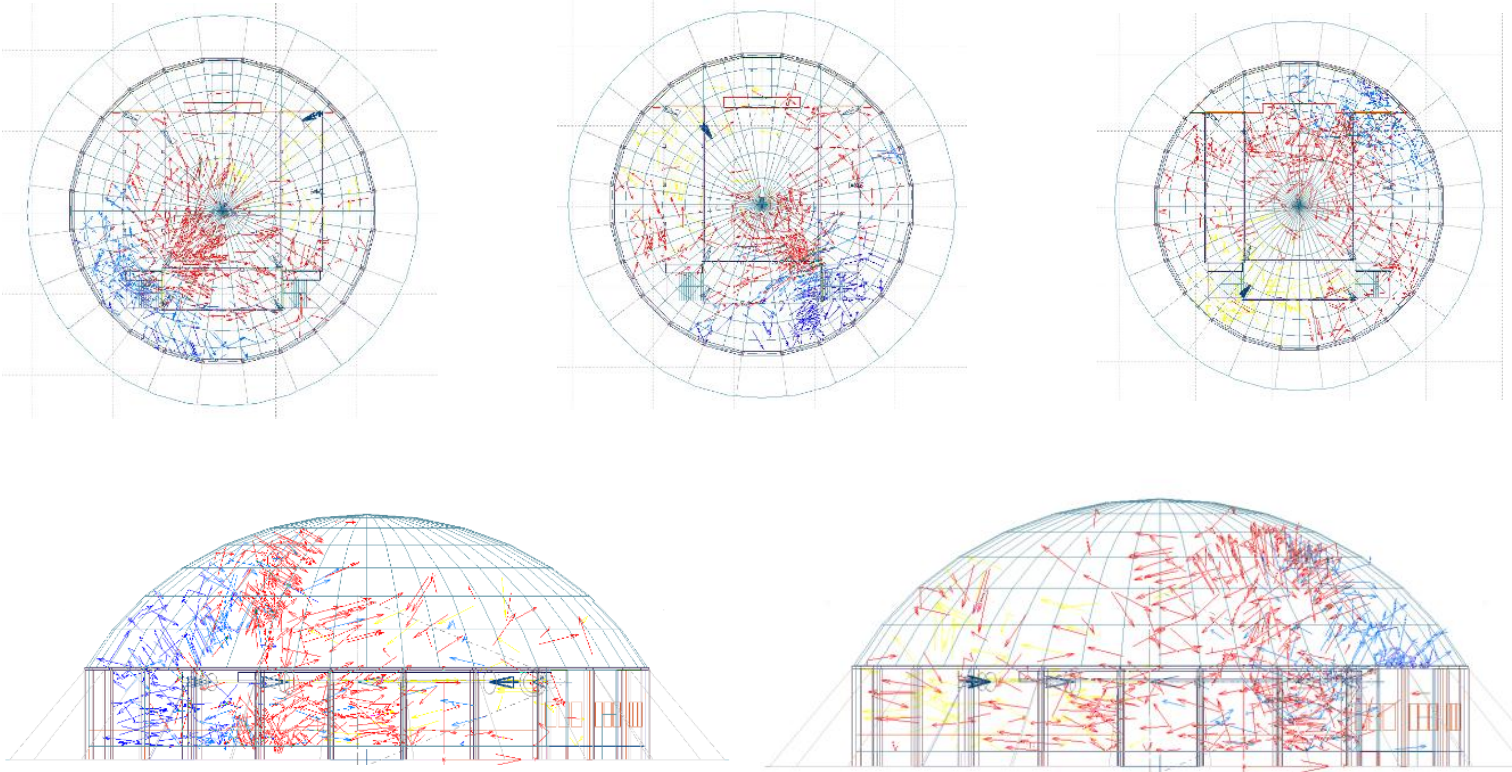

Gambar 6 Simulasi rays and pacticles speaker

(sumber : analisis ecotect)

Hasil visual dari rays dan particles dapat dilihat dari beberapa gambar diatas. Disetiap speaker terjadinya gema dan pemusatan suara pada ceiling masjid. Hal itu dapat dilihat dari sinar yang tidak menyebar keseluruh ruangan dan sinar berwarna merah menandakan penyebaran suara oleh speaker yang dipantulkan oleh elemen-elemen interior sehingga terjadinya gema. Pada penelitian yang dilakukan (Setiyowati,2008) dan (Priandi, 2012) mengatakan bahwa masjid yang berplafond atau ceiling kubah mengakibatkan pemusatan suara dan tingginya waktu dengung pada ruangan tersebut. Sama halnya seperti hasil visual pada gambar di atas.

Untuk mengatasi permasalahan tersebut peneliti akan membuat beberapa model pada ceiling masjid dan beberapa penambahan material serap dengan tujuan untuk mengoptimalkan waktu dengung dan background noise di dalam Masjid.

\section{d. Rekomendasi desain}

- Simulasi I (ceiling datar)

- Simulasi 2 (ceiling cembung)

- Simulasi 3 (ceiling berlevel)

Pemilihan ketiga model diatas berdasarkan teori dan penelitian yang telah dilakukan. Dalam penelitian yang dilakukan (icha, 2005) mengatakan ceiling datar menghasilkan nilai akustik yang baik. Sedangkan cembung memberikan suara yang jelas kepada para penonton yang duduk di deret paling belakang tanpa cacat dan perbedaan tempo penerimaan (Suptandar, 2004). Dan ceiling berlevel atau tidak beraturan akan menyebarkan bunyi langung ke arah audiens hingga ketempat duduk terjauh. (Ambarwati, 2009). 
Table 4. perbandingan nilai waktu dengung dari ketiga model

\begin{tabular}{|c|c|c|c|}
\hline $\begin{array}{c}\text { Alternatif } \\
\text { Model }\end{array}$ & $\begin{array}{c}\text { Frekuensi } \\
500- \\
\text { I000 } \\
\text { HZ }\end{array}$ & $\begin{array}{l}\text { Volume } \\
\text { Ruang }\end{array}$ & OPTIMUM RT FOR SPEECH 0,9-I,0I s \\
\hline Model I & $\mathrm{I}, 73$ & $2631.65 \mathrm{~m} 3$ & optimum RT untuk pidato dan penampilan musical \\
\hline Model 2 & $3,5 \mathrm{I}$ & $5454.43 \mathrm{~m} 3$ & Permukaan yang reflektif memperpanjang tempo gema suara \\
\hline Model 3 & $\mathrm{I}, 58$ & $5208,54 \mathrm{~m} 3$ & optimum RT untuk pidato dan penampilan musical \\
\hline
\end{tabular}

Sumber: analisis penulis

Tabel diatas merupakan hasil dari simulasi dari ke-tiga alternatif model yaitu ceiling datar, cembung dan ceiling model berlevel. Dari hasil tersebut dapat disimpulkan bahwa nilai yang paling berpengaruh yaitu pada model ceiling ke-tiga (berlevel), dengan nilai waktu yang didapatkan pada occupancy $0 \%$ sebesar 2,I3 s da pada occupancy 50\% sebesar I,58 s. Sehingga alternatif model ceiling ke tiga yang akan dipilih untuk dilakukan simulasi akhir dengan mengantikan beberapa material untuk menyederhanakan nilai waktu dengung dan background noise di dalam masjid.

\section{e. Simulasi Model Akhir}

Dalam simulasi akhir ini ada beberapa material yang ditambah pada ruang masjid Raudhaturrahman ini, yaitu padang ceiling masjid, dinding, dan lantai. Penyerapan oleh elemen pembatas ruangan sangat bermanfaat untuk mengontrol waktu dengung dan Background Noise. (Massikki, 20II).

Tabel 4 Nilai absorsi material

\begin{tabular}{|l|l|l|l|l|l|l|l|l|l|l|}
\hline \multirow{2}{*}{ no } & \multirow{2}{*}{ Material } & \multicolumn{2}{l|}{ Frekuensi } \\
\cline { 3 - 13 } & 63 & I25 & 250 & 500 & I000 & 2000 & 4000 & 8000 & I6000 \\
\hline I & Acoustic tile suspended & 0.06 & 0.06 & 0.13 & 0.47 & $0.9 \mathrm{I}$ & 0.94 & 0.78 & 0.74 & 0.70 \\
\hline 2 & Plaster joist suspended & 0,28 & 0,28 & 0,20 & 0,10 & 0,08 & 0,08 & 0,12 & 0,13 & 0,15 \\
\hline 3 & framedplywoodpartision & 0,17 & 0,1 & 0,07 & 0,07 & 0,08 & 0,05 & 0,04 & 0,05 & 0,04 \\
\hline 4 & solidcore pine timber & 0,17 & 0,14 & 0,12 & 0,08 & 0,08 & 0,07 & 0,06 & 0,05 & 0,04 \\
\hline 5 & plywood & 0,43 & 0.40 & 0.34 & 0.25 & 0.19 & 0.15 & 0.14 & 0.12 & $0.1 \mathrm{I}$ \\
\hline 6 & karpet & 0.03 & 0.04 & 0.09 & $0.2 \mathrm{I}$ & 0.34 & $0.5 \mathrm{I}$ & 0.63 & 0.63 & 0.58 \\
\hline
\end{tabular}

Hasil simulasi akhir setelah penggantian material menunjukkan perbaikan yang cukup signifikan terutama dalam kondisi jumlah pemakai sebanyak 50\% - I00\%. 


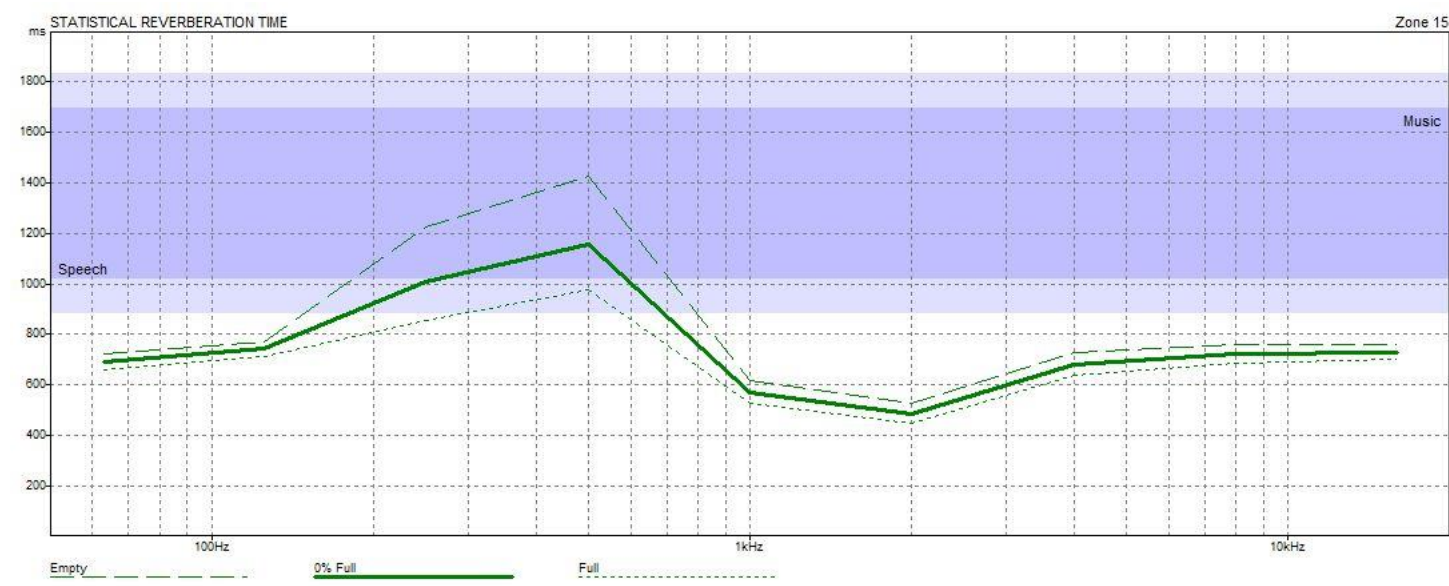

Gambar 7 Grafik waktu dengung dengan occupancy sebesar 0\%,50\% dan I00\% setelah pergantian material

Sumber: Analisis ecotect

Table 5 nilai waktu dengung (reverberation time) occupancy 0, 50 dan I00\% s

\begin{tabular}{|c|c|c|c|}
\hline & EMPTY & $50 \%$ & FULL \\
\hline FREQ. & $\mathrm{RT}(60)$ & $\mathrm{RT}(60)$ & $\mathrm{RT}(60)$ \\
\hline -------- & ------- & ------- & ------- \\
\hline $63 \mathrm{~Hz}:$ & 0.72 & 0.69 & 0.66 \\
\hline I25Hz: & 0.77 & 0.74 & $0.7 \mathrm{I}$ \\
\hline $250 \mathrm{~Hz}:$ & $\mathrm{I} .23$ & I.OI & 0.85 \\
\hline $500 \mathrm{~Hz}:$ & $\mathrm{I} .42$ & I.I6 & 0.98 \\
\hline IkHz: & 0.62 & 0.57 & 0.52 \\
\hline $2 \mathrm{kHz}$ & 0.53 & 0.48 & 0.45 \\
\hline $4 \mathrm{kHz}$ & 0.73 & 0.68 & 0.64 \\
\hline 8kHz: & 0.76 & 0.72 & 0.68 \\
\hline
\end{tabular}

Sumber: analisis ecotect

Sebagaimana tampil dalam grafik dan tabel hasil penghitungan dengan Ecotect diatas, hasil yang di dapatkan pada saat kondisi ruang 0\% ialah.I,42 s, akan tetapi pada saat ruang terisi $50 \%-100 \%$ terlihat angka sudah sangat mendekati dengan angka ideal yaitu I.02 s pada frekuensi $500 \mathrm{~Hz}$. Jadi, dari hasil di atas dapat disimpulkan bahwa kondisi ruang akustik dengan model ceiling berlevel dan pergantian material yang digunakan jauh lebih optimal dibandingkan dengan kondisi eksisting ceiling cekung. Karena, kondisi akustik masjid yang baik bukanlah sebuah kemewahan tetapi kebutuhan (Mariani, 2008). 


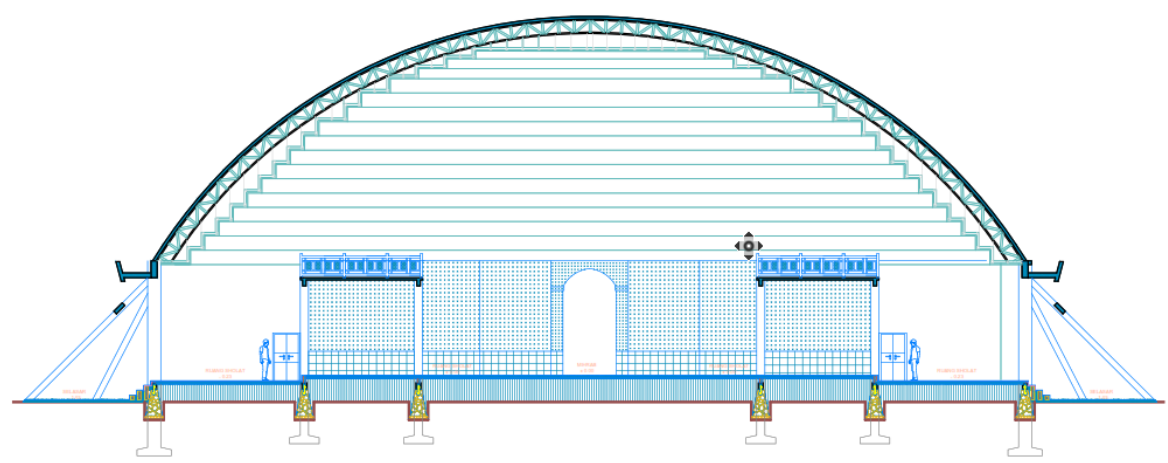

Gambar 8 gambaran ceiling berlevel

(sumber : pribadi)

\section{Kesimpulan}

Dari hasil penelitian yang telah disimulasikan, maka dapat disimpulkan bahwa kualitas akustik pada masjid Raudhaturrahmah ini tidak bagus. kondisi masjid Raudhaturrahmah mengalami cacat akustik khususnya waktu dengung dan background Noise yang sangat signifikan. Penyebab terjadinya background noise dikarenakan letak masjid berada di dekat jalan raya, hampir semua permukaan dinding adalah bukaan dan terlalu banyak menggunakan material yang bersifat pemantul serta bentuk cekung yang ada sebagai ceiling masjid. Solusi untuk mengoptimalkan akustik masjid Raudhaturrahmah ialah dengan membuat ceiling yang yang berlevel untuk mencegah pemusatan suara dan penambahan material serap agar suara tidak memantul dan menyederhanakan Background Noise. Hasil simulasi dengan penambahan ceiling berlevel dan material serap nilai RT lebih optimal.

\section{Daftar Pustaka}

Doelle, L.L. I990. Akustik Lingkungan. Erlangga. Jakarta.

Ecotect Analysis Document, 201 I

Ernaning setiyowati, sri nastiti, 2008, nilai kualitas akustik ruang pada masjid masjid di daerah permukiman dengan bentuk plafon yang berbeda, jurnal rekayasa perencanaan, Vol, 4. No 2 .

Hasan, Iqbal, 200I. Pokok-pokok materi metodologi penelitian dan aplikasinya, Ghalia Indonesia, Jakarta

Icha, S.V., Soegijanto, R., Triyogo, A. (2005) "Study on the Effects of Ceiling Shape to the Acoustics Condition of Masjid by Means of Computer Simulation”, Proceedings of the 6 th International Seminar on Sustainable Environment and Architecture, Jurusan Arsitektur, Institut Teknologi Bandung, Indonesia, hal. 23-27

Lawrence, Anita, I970, Architectural Acoustics, Applied Science Publishers Ltd, London.

Mariani dan Nurlaela Rauf , 2008, Deskripsi Kondisi Akustik Ruang Masjid Al Markaz Al Islami Makassar, Jurnal SMARTek, Vol. 6, No. 4.

Massiki, Muhammad nadjib, 20 I I, Desain Akustik Ruang Sholat Masjid Agung Darussalam Palu, Jurnal Ruang, Vol. 2 No. I

Mediastika, C.E. 2005. Akustika Bangunan, Prinsip-prinsip pada Penerapannya di Indonesia. Erlangga. Jakarta.

Nur Rahmawati Syamsiyah, Sentagi Sosetya Utami, Atyanto Dharoko 20I4, kualitas akustik ruang pada masjid berkarakter opening wali design (studi kasus: masjid Al-Qomar purwosari surakarta), simposium nasional RAPI XIII

Riza priandi, 2012 pengaruh letak titik fokus kelengkungan kubah terhadap kinerja akustik ruang masjid, RUAS, edisi II, Vol. I. 
Satwiko, P. 2009. Fisika Bangunan. Andi. Yogyakarta.

Suptandar, P.J. (2004), Faktor Akustik Dalam Perancangan Desain Interior, Djambatan, Jakarta.

Sarwono, S.W. 1995. Psikologi Lingkungan. Grasindo. Khairuddin, arif kusumanto, 20I I, rekayasa material akustik ruang dalam desain bangunan studi kasus rumah tinggal sekitar bandara adisutjipto yogyakarta, Forum teknik, Vol.34 no I. 